\title{
Everyday geographies in the changing city: subjective photo-routes in Mandalay, Myanmar
}

\author{
Matteo Puttilli
}

Published online: 31 July 2020

(C) The Author(s) 2020

\begin{abstract}
This work upholds the importance of questioning young people to find out their point of view on urban transformation and grasp their perception and representation of the changes. Hence, the paper presents the methodology and results of an autophotography activity, and more specifically photo-routing organized in March 2018 with a group of young undergraduates at Mandalay University, Myanmar. In the sphere of this activity, the participants were asked to reflect on their relationship with the urban space and to use a camera to capture significant places and situations in their everyday experience of the city, with the goal of exploring their personal point of view on the changes occurring in it, both from a tangible and intangible perspective, in addition to how they are reflected in the everyday practice of the city. The idea at the basis of the research-intervention is that the focus on everyday life through qualitative and visual
\end{abstract}

The intervention was carried out in collaboration with Stefano Bartolini, at the time research fellow at the University of Florence, who took part in devising and conducting the activity and took care of the technical aspects linked to the acquisition of the geo-referenced images on GIS. Thanks also go to Dr. Nyo Nyo, Professor and Head of the Department of Geography and Environmental Studies at the University of Mandalay, for her logistical and organizational support.

\section{Puttilli ( $\square)$}

Department of History, Archaeology, Geography, Fine and Performing Arts, University of Florence, via San Gallo 10, Firenze 50129, Italy

e-mail: matteo.puttilli@unifi.it investigation techniques enables the emergence of some of the-both conscious and not-more-thanrepresentational ways in which people-a group of young adults in this specific case-perceive and live the processual nature of the city. Results show that the photo-route tool proved to be particularly effective in stimulating a critical gaze on the city and the changes underway, to acquire awareness of the constantly inbecoming nature of the places and reflect in an introspective manner on their own life course in relation to the city. Thus, the paper provides a contribution "from below" to the reflections on urban transformations going on in Southeast Asian cities and, more precisely, in Myanmar.

Keywords Photo-routes · Young adults · Urban change $\cdot$ Mandalay

\section{Introduction}

In a recent introduction to a special issue of the Children Geographies journal focusing on the future of young people in Asia, Susanne Naafs and Tracey Skelton (2018) reflect on the changes underway in what can be considered "the most dynamic region on the planet". All over the continent, albeit with great inhomogeneity in the different areas, cultural, political, institutional, social and economic transformations 
are combining in an explosive urbanization process that has no equal anywhere else in the world. It is a transition affecting all spheres, hence the young generations find themselves living and growing up in completely different contexts to the generations that came before them, having "to navigate their way through this maelstrom of change from a position of newness and originality" (p. 5).

Starting from this initial cue, this work upholds the importance of questioning young people to find out their point of view on these transformations and grasp their perception and representation of the changes. Hence, the paper presents the methodology and results of an autophotography activity (Lombard 2013), and more specifically photo-walking organized in March 2018 with a group of young undergraduates at Mandalay University, Myanmar ${ }^{1}$. In the sphere of this activity, the participants were asked to reflect on their relationship with the urban space and to use a camera to capture significant places and situations in their everyday experience of the city, with the final goal of exploring their personal point of view on the changes occurring in it, both from a tangible and intangible perspective, in addition to how they are reflected in the everyday practice of the city.

The idea at the basis of the research-intervention is that the focus on everyday life through qualitative and visual investigation techniques enables the emergence of some of the-both conscious and not-more-thanrepresentational ways in which people-a group of young adults in this specific case-perceive and live the processual and in-becoming nature of the city. The intervention described here hence slots into a wider set of personal research experiences in the field of visual and multimedia methodologies in urban geography (Aru et al. 2017; Governa and Puttilli 2016; Puttilli et al. 2016). In turn, it is connected to the now vast debate on the use of ethnographical and social research methodologies centred around multimedia, visuality, autobiographical storytelling and mixed methodologies (Dicks et al. 2006; Hurdley and Dicks 2011; McQuoid and Dijst 2012).

Specifically, the research-intervention took place within an exchange programme between the University of Florence and Mandalay University, giving the teachers and students of the two universities the opportunity to spend study and research periods at the partner institution. As part of one of the various missions to Mandalay University, a workshop was organized which saw the participation of 21 undergraduate students. The workshop consisted of five meetings, during which teachers and students shared the theoretical background and methodological lines of the research. After this, the students worked independently - alone or in pairs - to produce photoroutes through the city. Lastly, the results were presented and discussed together. The work is also based on more in-depth and long-term knowledge of the local context, acquired in an extensive on-site research project to collect data and functional information for the preparation of a sustainable tourism development plan for the area of the ancient cities of Upper Myanmar (LaGeS 2016), which the University of Florence-Laboratory of Social Geography was commissioned to perform by the Italian Ministry of Foreign Affairs and International Cooperation.

The article is organized as follows: after the introduction, the second section situates the research within the wider debate on urban transformation going on in Southeast Asia and in Myanmar; the third section presents the research context and the main aspects of the rapid urbanization process in Mandalay; the fourth section presents the theoretical and methodological premises of the work and illustrates how the photoroute technique was used in this specific case; section five gives a summary of the results of the activity and investigates three core topics that emerged from the photo-routes; lastly, section five and six make a critical reflection on the students' processing of urban change in Mandalay and on the role of photoroutes and visual methodologies in grasping the always inbecoming and transitional nature of places and subjectivities in space.

Questioning urban change in Southeast Asia and Myanmar

If there is a macro-area on the planet in which studying the everyday life experience of major social changes at the urban scale is meaningful, it is probably Asia-and in particular Southeast Asia for this specific case. As mentioned in the introduction, Southeast Asia can be considered not only as the most dynamic area on Earth, but also as the most urbanised, globalised and rapidly changing area of the planet (Yeung 2002; 2011; World Bank 2015), with major consequences in different spheres. Although providing a detailed description of the processes going on in the region 
goes beyond the objectives of this paper, some considerations on their intensity and consequences may be useful to better clarify what-in the context of this paper-is referred to as urban change.

According to Yeung (2011), Southeast Asian cities have been progressively going through four major transformations over the last decades. i) An economic transformation - as they have been rapidly industrialized and integrated into an intricate network ofexisting and planned-globalized gateways and regional corridors (Rimmer and Dick 2019). Hence, many cities have become the engine room of their nations economic growth and some of them ascended among the actual nodes of the world economic system. ii) A physical transformation-as they rapidly passed from being pedestrian urban entities to dense populated urban agglomerations, intensively infrastructured and continuously expanding their urban fabric towards the countryside and peri-urban areas. iii) A social transformation-as they have been subjected to a substantial increase in the urban population due to migration from rural areas (or their incorporation in the urban expansion) and the rise of a middle class with new lifestyles, consumption behaviours and aspirations (Bunnell, Goh and Ng 2019), though contrasted by a high and persistent poverty rate. iv) An informational transformation-as they have been accounted for as world leaders in the development, diffusion and adoption of ICT and telecommunication infrastructures, revolutionizing people's understanding of time, space and distance rapidly (as also explained in the empirical section of this paper).

While these changes have occurred over at least four decades, the processes of urbanisation are considered to still have a long way to proceed in the region (Jones 2019), as the global share of population living in urban areas is lower than other regions (47\% in 2015) (UN 2018), albeit with marked differences between countries (Jones 2019). According to a recent report issued by the World Bank (2015), urbanisation in East Asia is just at the beginning and "the region will continue to urbanize rapidly as economies shift from agriculture to manufacturing and services, with several hundred million people migrating to cities over the next two decades" (p. XV). Although important differences exist between divergent countries and there is not a unique pattern of urbanization, another distinctive feature of the region needs also to be considered in the framework of this study, namely the role of secondary cities as the main driver of urbanisation (Rimmer and Dick 2019). This role results from the fact that megacities do not house a very high share of Southeast Asian urban population, while an increasing rate of this lives in places variably defined and classified as either secondary cities, intermediate cities or larger towns (Sheng 2011; Jones 2019), and in any case smaller than 5 million people.

Nonetheless, transformations are always ongoing, not without contrasts. With Sheng (2019, p. 31): "Southeast Asian cities are changing wholesale. In the core, skyscrapers replace older buildings to put lands to its most profitable use, increasing congestion as street patterns do not change. In the periphery, land is converted for urban use to accommodate the city's expansion, but often with little or no planning or coordination". The processes of urbanisation carry along major issues and challenges that cannot be detailed here. These include contrasting growing social inequalities and providing basic services and facilities to the growing population, coping with environmental problems caused by urban development and expansion, strengthening local institutions and governance systems (Sheng 2011; UN-Habitat 2015).

If compared to other countries in the region, Myanmar is clearly considered as a latecomer. Although the country's population remains largely rural (with just $30 \%$ of the population living in cities) and there are no large urban areas by East Asian standards (World Bank 2015; Roberts 2019), urbanization is currently developing at a rapid pace. Although the lack of reliable and up-to-date data on population is a major problem regarding Myanmar, based on the 2014 Census, the two largest cities in the country are Yangon and Mandalay, where the resident populations are estimated to be 4.7 and 1.3 million, respectively. By 2030, the population living in cities larger than one million persons is expected to grow from 5.8 million to 9.2 million, with an increase of about $58 \%$, mostly concentrated in the two main urban poles of Yangon and Mandalay. Also, the number of cities counting between 100,000 and 500,000 residents is estimated to be more than double, i.e. from 28 to 61 (Union of Myanmar 2016a; Vaughan 2017). Consequently, in the next years it is likely that Myanmar will rapidly pass through many of the above-described transformations occurred in neighboring countries.

Nonetheless, it must be stressed that the above mentioned transformations are happening in a peculiar 
political context, and are charged with strong ideological and symbolic meanings. Urbanization and urban change, indeed, are incorporated into a government and elite-led "transitioning" narrative, and are ascribed with a crucial role in the dramatic sociopolitical change towards a "new, modern, and developed nation" (Roberts 2019, p. 400). In fact, urban change in Myanmar is not simply a matter of sociospatial transformation, but it also plays a crucial role in supporting the challenging and problematic transition from military to semi-constitutional government and in the process of nation-building (Huynh 2018; Roberts 2019). At the same time, as Rhoads and Wittekind (2018) argued, the omnipresent reference to the transition framework when dealing with Myanmar issues is highly problematic and biased. Indeed, it conveys a superficial, linear, and unquestionable conception of the country's recent history, present and future (from isolation and decline to development and modernity), and, more importantly, it silences the contested nature of ongoing transformations, as well as their impact on and ruptures of preexisting social structures and territories. Concerning the field of urban studies, for example, the pressure to stimulate urban growth and attract foreign investments favors the development of a highly centralized and top-down approach to city planning, based on international standards and globalized matrices that generally ignore local specificities and ethnic diversities (Roberts 2019) and often replicate a colonial and authoritarian model of land control and urban governance based on forced evictions and land grabbing (Rhoads 2018).

In the end of this preliminary itinerary over urban change in Southeast Asia and Myanmar, we agree with Roberts (2019) on the fact that cities in Myanmar have not yet been much studied from inside, leaving urban change difficult to be documented and analyzed. This aspect is of particular relevance in light of the highly intangible features of urban change such as that related to political, societal and cultural aspects, local identities, and everyday experiences and perceptions. The majority of studies on the processes of urbanization in Myanmar seen "from below" (that is, from the perspective of citizens) are recent and mostly centered on Yangon (Matelski and Sabrié 2019; Sabrié 2019; Kyed 2019; Forbes 2019; Hong 2020), with the exception of a survey located in Bagan and mostly related to the impact of tourism development (Rick and Franck 2016).

While this shortage of studies is particularly evident in the case of Myanmar, a similar case can be found for other Southeast and East Asian countries as well. In fact, as urbanisation processes and their effects in the region are stressed and highlighted by several institutional sources and academic surveys, this paper argues that a much less investigated area of the Southeast Asian urbanization deals with how these processes are lived, perceived, and experienced by people (especially if compared to Western countries). Making reference to Brenner and Schmid's paper on urban epistemologies (Brenner and Schmid 2015), it appears that the impressive processes of concentrated, extended and differential urbanization taking shape in Southeast Asian cities are much more studied with regard to two of three main analytical dimensions. In particular, studies have focused on spatial practices and territorial regulations, while the focus on the (third) dimension of everyday life-i.e. how these processes affect social routines, everyday experiences and forms of life-is still underrepresented. This is not surprising as one of the major shortcomings of contemporary urban studies is that they tend to be "completely out of touch with the lived experience of city residents", as pointed out by Schindler (2017, p. 48). Therefore, this paper aims at contributing in this field of research, focusing on the everydayness of urban change in an intermediate Southeast Asian city, such as Mandalay.

The local context: mandalay

As Youngmi Kim (2018, p. 274) effectively pointed out in a recent article in Cities, Mandalay is "a frequently mentioned but little studied city, which is undergoing significant change in its urban fabric and socio-economic landscape”. In effect, Mandalay's reputation is based more on the mythical aura conjured up by its name and historical and literary reverberations than its growing role in the regional urban hierarchies. Kim's article is indeed one of the few studies published in international journals that concentrate on the city and frame its role in the wider national and macro-regional context, in particular emphasizing the rapid and intense urbanization process which the city is undergoing and the implications of this process in terms of regional governance. 
Indeed, despite the little consideration in the literature, Mandalay is playing an increasingly significant role from the geopolitical, demographic, economic, and lastly, symbolic point of view. Founded quite recently (1856), Mandalay is located at the centre of a large flood plain created by the River Irrawaddy, in a strategic position at the centre of some the main longdistance road links and international routes in the context of the wider area at the juncture of Southeast Asia and South Asia (Thant Myint 2011; LaGeS 2016) (Fig. 1).

This peculiar location somehow reflects at a minor scale that of the whole Myanmar which, given also its resources and natural endowments, "finds itself at the centre of political wrangling between major powers" (Malik 2018, p. 362) with China traditionally exerting a geopolitical and strategic pressure over the country.

It is not surprising that from 2006 Mandalay is included into the northern one of the six newly added corridors belonging to the Greater Mekong Subregion network, firstly designed in 1998 by the Asian
Development Bank (ADB) with the aim of establishing a multimodalland-transport transnational infrastructure (Rimmer and Dick 2019); nor that, due to its vicinity to China, Mandalay is considered as a focal point in the Chinese expansion strategy in the region through the One Belt One Road Initiative (Gong 2019) and, more precisely, the China-Myanmar Economic Corridor (CMEC). Officially launched in 2018, and building on recently ultimated gas and oil pipelines (Zhao and Yang 2012), the CMEC aims at developing a road and rail transportation route from Yunnan Province in China through Muse and Mandalay to Kyaukpyu in Rakhine State, including a notable railway project connecting Muse to Mandalay. Even though it is publicly considered as a mutual economic opportunity for both Countries, the corridor is contested under several perspectives (Zhou 2019; Heinrich Böll Stiftung Yangon 2019). As an example, there is scepticism around the increasing influence of China in Myanmar and the democratic and transparent management of some sensitive internal affairs, such

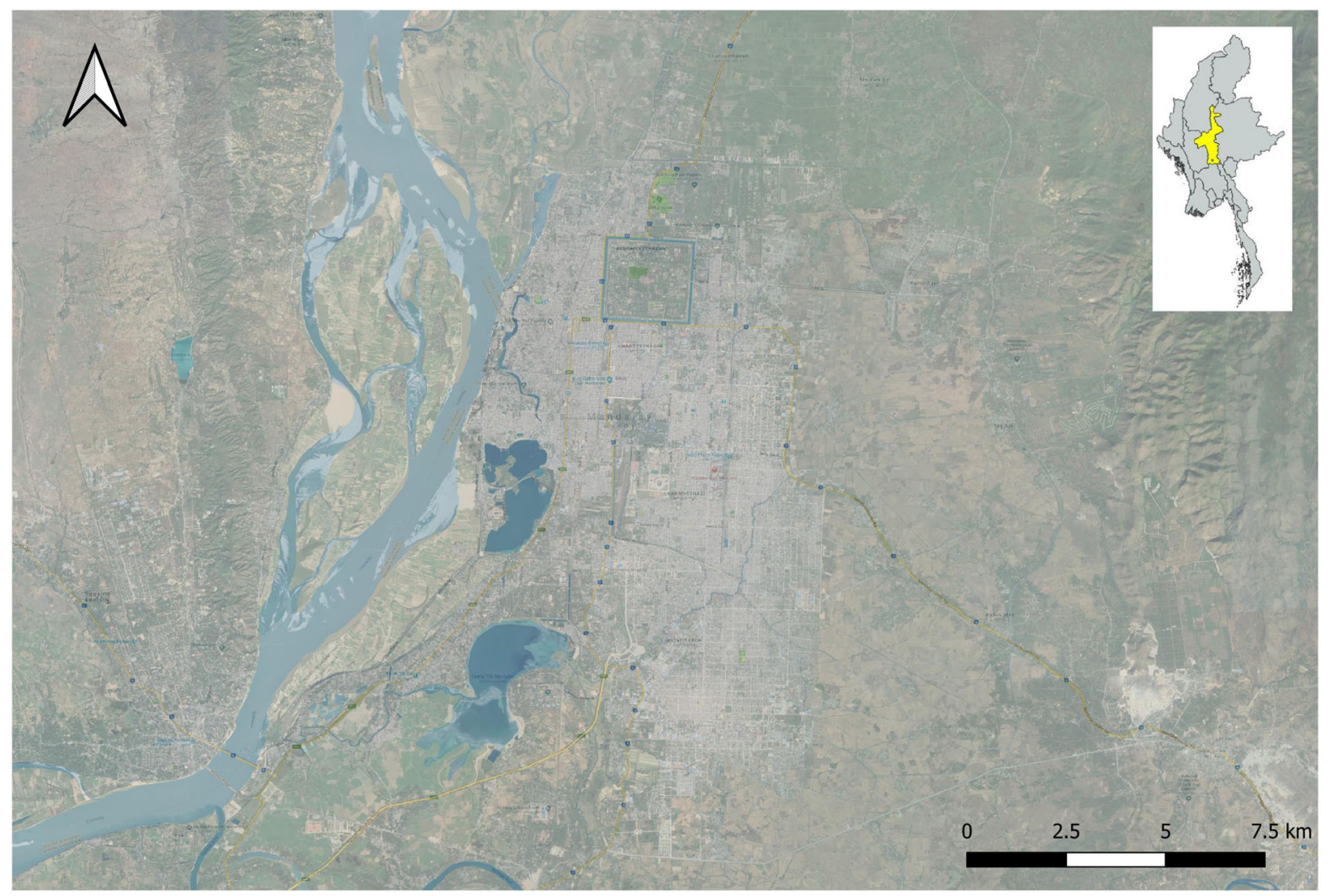

Fig. 1 Map of Mandalay and surroundings Source: LaGeS 2016 
as procedures of land acquisition and compensation, environmental protection, and stakeholder involvement (Taidong 2019). Moreover, the initial project went through significant downscaling and delays after its first launch (Sun 2019). Nevertheless, CMEC still symbolizes the geopolitical role attributed to Mandalay in the region and the growing interests the city is invested by.

As already mentioned, even though no precise knowledge of the resident population is available, according to different estimations the city hosts between 1.3 and 1.7 million inhabitants, making it the second city in Myanmar after Yangon (Union of Myanmar 2016b). Besides, the growth of Mandalay's urban population is a relatively recent as well as particularly intense phenomenon, since its population has tripled over the last three decades, also due to recent waves of migration from the countryside (Nyo 2016). In line with the trends in the rest of the country, the urban population is undergoing further rapid expansion and growth of up to 4 million people is forecast in 2040 (ADB 2015). The analyses conducted by the LaGeS (2016) also show how the population in the metropolitan area of Mandalay is mainly a young population, in which over- $65 \mathrm{~s}$ make up just $6 \%$ of the total.

Population growth has clearly been accompanied by a significant urban expansion process, which is set to continue in the near future. In the context of Myanmar's development strategy and of the Urban Development Plan for Mandalay, indeed, the city is identified, along with Yangon, as one of the two poles in the "two-polar growth model" at the centre of the vision forthe nation's economic evolution in the next 20 years (ADB 2014; Union of Myanmar 2016a, b). This development model foresees a process of further industrialization and huge investments in national and international road, air and rail transport systems, as well as in the development of the existing river port, in view of making Mandalay a centre for the development of the northern part of the country as well as a new, complex and growing trade hub in the heartland of South-East Asia (LaGeS 2016; Kim 2018). As already mentioned, this role is further pushed by its privileged relationship with China. Since the end of the 1980s, Mandalay has been at the centre of a growing flow of people, assets and capital from nearby China, making the city increasingly dependent on its bigger neighbour to the north. Some estimates claim that Chinese inhabitants today make up $30-40 \%$ of Mandalay's entire population, with a dominant role in the commercial, tourism, catering and entertainment sectors (Kim 2018).

As a consequence of the pressure induced by population and economic growth, the urban fabric is undergoing significant changes (Union of Myanmar 2016b): in the central area of the city located around the Royal Palace, traditional commercial and business low buildings are reconstructed and replaced with five to six-storey buildings, while some buildings are reconstructed to seven to tenstorey commercial edifices along the major arterial roads. The same is happening to residential houses, progressively converted into apartment buildings of four to six floors. Outside of the central area, high density residential area with small-scale wooden buildings spread to the southern peripheries of the city, where new ordered residential developments integrated with business and commercial facilities are being realized, in sharp contrast with the surrounding urban environments.

Mandalay's expansion process is not without its contradictions or problems. Indeed, while Myanmar's planning approach to date was mainly focused on infrastructure and big-picture planning (Dobermann 2016; Kim 2018), and normally conformed to international standards with almost no local consultations (Roberts 2019), "the city has been governed on the basis of fairly dated municipal laws that go back several decades" and "a strongly hierarchical, compartmentalized and dysfunctional governance structure" (Kim 2018, p. 283). Consequently, again Kim (2018, p. 276) furtherly observes that, "as a result of population growth fuelled by recent economic development, Mandalay has become a crowded city, with decaying infrastructure, a lack of public services, including road congestion, high pollution, limited access to affordable housing, and equally scarce employment opportunities". Moreover, Mandalay also incorporates several informal settlements made of barracks and shanties, as well as former rural settlements progressively integrated within the urban area as the city expands. Albeit different, both these contexts house populations living in extremely precarious conditions, facing increasing pressure to move out or risking eviction as new development plans and construction projects are moved forward (Khaing and Zau Zin Myat 2019). 
Hence, the challenge for the city governance in the next decades consists of the capacity to accompany economic growth and urban expansion with interventions in the social, environmental and infrastructural field which enable an increase in the quality of the population's urban life. This is the direction followed by projects and interventions supported by numerous actors in the international community (from the UNHabitat programme, through the Asian Development Bank to the European Union, to quote the most significant ones, in addition to a multitude of other states and organizations engaged in cooperation interventions).

Lastly, the symbolic role played by Mandalay as one of the country's most important religious, historical and cultural centres should also be mentioned. The vaster metropolitan area of Mandalay is indeed a region with unique characteristics since it hosts the biggest concentration of sites dating back to the different phases of the Bamar civilization (the main ethnic group in Myanmar) (LaGeS 2016): in addition to Mandalay, the last capital of the kingdom prior to the British occupation, the nearby cities of Amarapura and Innwa also played political and administrative roles in previous eras, as did Sagaing and Mingun in the cultural and religious spheres. Some tangible signs of these roles remain in the area, principally the remains of the royal cities, then the countless pagodas and mausoleums from the most diverse eras and styles, single monuments and archaeological sites, some of which require urgent restoration and maintenance work. At the same time, the area continues to preserve a conspicuous and established intangible cultural heritage, testimony of the population's everyday culture which is expressed in the artisan workshops and districts present in the rural villages, as well as cultural-religious events and practices, and local food culture. The city's cultural importance is also reflected in its growing position on the national and international tourism routes. Following the country's opening to international tourism in 2011, Mandalay recorded just over 100,000 arrivals in 2012 and almost 1 million in 2015, with the possibility of exceeding 2 million arrivals in 2021 according to the most optimistic forecasts (LaGeS 2016). Clearly, as has already happened in other areas of the country (Rick and Franck 2016), tourism will constitute another important factor in the city's transformation, in economic as well as social and cultural terms.
(Shooting) the everydayness of urban change

As anticipated in the introduction, the goal of this research intervention is to investigate how a group of young students perceives, lives and represents the urban space and the transformations underway in there, in addition to how these transformations are reflected in the everyday practice of the city. The idea at the basis of the investigation is that by observing lived experiences, representations and practices, it is possible to grasp the sense-or, better, the multiple levels of sense and meaning-of how the city is changing and what is at stake in the current transformation as regards young people lives and identities.

Thus, this paper is situated into the much wider debate on young citizens' experience of major social changes and the subsequent understandings, images, representations, and narrations of these same changes. Indeed, a significant body of literature has investigated the different ways in which major socio-spatial transformations, such as globalisation processes, affect the unfolding of young people identities and the transition to adulthood in the interplay between global forces and individual everyday practices. As argued by Holloway and Valentine (2000) and furtherly analysed by Hörschelmann and Schäfer (2005; 2007), young people are affected by social changes, yet they are able to construct levels of understanding and response to these changes, as well as they are proactive in the construction of their own lifeworld. In this regards, geographers played an important role in the production of knowledge on young people lives, socio-spatial identities and material practices (Evans 2008; Skelton 2009; 2013) and in revealing to which extent space and time are integral in their perception of transition to adulthood (Worth 2009) and, more generally, in the process of construction of social identities (Massey 1998).

In these reflections, the spatiality of everyday life is ascribed with a special value. As Valentine (2003, p.48) argues with regard to young people with the same age of the participants to this research, indeed, the exploration of everyday spatiality sheds light "on the importance of different life spaces and the interconnections between them" and on "how young people 16-25 are both actors in space and constrained by it". In the understanding of young people interaction with their everyday worlds, Schlemper et al. (2018, p. 607) stress the importance of considering 
their spatial narratives as they "consist of how we perceive various places, whether through direct or indirect experience, and how we interact (or don't) with these places and why. (...). The spatial narratives that we carry with us shape the way we view the world and our place in it because they are reflective of our perceptions (and misconceptions) about places".

Thus, considering young people's voice on their lived space is of two-fold importance: firstly, as it can add a perspective, usually under-valued and nonrecognized, on their living contexts, unveiling problems and envisaging solutions; secondly, as it can reveal unexpected features characterizing urban change that normally escape more institutionalized analysis issued by urban scholars, an example being how urban changes are perceived to affect young people lives. In order to investigate young people everydayness, the research draws inspiration from the rich and varied debate on the "practice turn" (Schatzki 2001) and more-than-representational approaches in geography and beyond (Lorimer 2005; Thrift 2008; Cresswell 2012). In fact, among the many possible aspects touched on in the reflection on these approaches, an essential contribution is given by the importance attributed to the everyday and ordinary dimension of practices as the foundation of people's understanding of the world (Simonsen 2007; Pyyry 2016; Crouch 2017). Making reference to Everts et al. (2011) interpretation of Schatzki's work, practices are here intended as a nexus of "specific ways of doing and saying things, for example ways of consuming, working, or socializing" (p. 323). Practices "are neither fully intentional nor fully routinized but consist of both elements to varying degrees" and are connected with emotions, materiality, and knowledge. From this perspective, it is important to remark how the concept of practices should not be only limited to concrete action in space but include "bodily doings and sayings alike, and that it would be a mistake to grant priority to one over the other" (Simonsen 2007, p. 171). Anderson and Harrison (2010) insist on this point, claiming that the representations should be taken seriously and "apprehended as performative in themselves; as doings". Practices and languages, actions and meanings are therefore all integral parts of a wider human expression in space, in the form of performative practices generated and produced on a daily basis. In research on everyday life, it is therefore fundamental to consider both what is done and what is sensed and narrated closely together, in order to capture the intimate connection between lived experiences themselves and storying lived experiences, and between action in and perception of the urban space and the changes underway in it.

In line with these presuppositions, the research made use of a mixed methodology, starting from subjective reflection on the lived space and developed through the realization of autophotographical paths in the urban space. Much has been said about the role of photography and, more specifically, autophotography as a tool to investigate the experience of space and the layered meanings, values, and subjective and collective atmospheres in the sense of place (Rieger 1996; Rose 1996; Dodman 2003). Adopted in multiple research contexts, using different technical solutions with different names (Lombard 2013) — such as photovoice, photo-elicitation, reflexive photographymethodologies centred around autophotography generally directly involve the participants in the research as co-researchers producing meaning on the places and spaces under investigation (Meth and McClymont 2009). The possibility of fostering non-verbal language and heterodox and creative manners of expression and communication through photography renders these techniques a particularly effective way of making generally under-considered and divergent points of view emerge (Dodman 2003; WoodleyBaker 2010; Cattedra et al. 2018). Hence, autophotography is used with subjects and social groups commonly considered "marginal" and disadvantaged and in social-participatory or pedagogical-educational contexts in which the goal is to give a "voice" to specific requirements and stimulate social action (Wang 2006; Griebling et al. 2013).

Although these more "political" implications of visual methodologies have recently been subject to critical reflection, in particular questioning their effective inclusivity and capacity to produce social change (Packard 2008; Pauwels 2015; Fairay 2017), there remains strong consensus around the usefulness of these tools in portraying the perceptive, qualitative, multisensorial and emotional dimension of the experience of space and in investigating the sphere of meanings associated with places (Lombard 2013; Leonard and McKnight 2015; Pyyry 2015). For these reasons too, autophotography has proven to be particularly effective and is widely used to explore urban spaces and practices as they are particularly "dense" 
in possible layers of meaning and sense (Hunt 2014). In this research, thus, photography is considered as a spatial practice in a double sense: first, as it is performed in space, on the base of an active engagement with place through the body; secondly, as it conveys open and multiple levels of meanings, interpretation, and narratives of everyday urban lives.

\section{Photo-routes through the streets of Mandalay}

In the specific case of Mandalay, we had the opportunity to work with a group of 21 students, equally distributed by gender and coming from three different study areas: archaeology, geography and anthropology. Ten of the participating students were born in Mandalay or places nearby (for example, in the nearby region of Sagaing); Eleven students instead came from other states in Myanmar and had chosen Mandalay as the place to attend university. In terms of housing, the group again was split into two quite balanced halves: those who lived in the city and those who lived in the university residence on the main city campus. Overall, it was a group of participants as homogeneous in terms of age, social extraction and conditions as it was heterogeneous in terms of places of origin, familiarity with the city, the way of living and inhabiting it and, as a consequence, also the perception of the changes underway within it. The group of students was involved in a cycle of five meetings each lasting one morning. In the first introductory meeting, the main aims of the intervention and the methodology were illustrated. Here, Mandalay was presented and discussed with students as a city intransformation, that is a city that is undergoing significant changes both from the tangible and intangible point of view. It worth clarifying, though, that in this first phase concepts like urban change and urban transformation were deliberately used as an open and multidimensional interpretative keys rather than rigid and sharp explanatory concept, in order to leave the students free to give their personal interpretation of them. No detailed descriptions of urban changes going on in Mandalay were given (even if examples were made), nor these changes were ascribed with any type of positive or negative value.

In a second phase, the students were asked to reflect on their personal experience of the city according to a question-stimulus sheet inspired by the one proposed by Jelena Savić for a cultural mapping project of Porto
(Savić 2017). In particular, the students were invited to locate and represent the places they most frequented and appreciated (or least appreciated) in the city, the ones ascribed with a positive or negative value (and why), the ones that they would like to change or preserve and the ones affected by the biggest transformations; they also had to express their more "sensorial" relationship with the urban space, namely the places where they perceived certain atmospheres, such as the smell, sound and colour associated with Mandalay.

A feedback session on the activity results was then undertaken, with all the students presenting and commenting their reflections. It must be specified that the activity was presented to students as being mainly focused on documenting their personal relationship with the city and the places considered as the most meaningful to them (both in positive and in negative terms).

While various tangible and intangible transformations going on in Mandalay were obviously mentioned and discussed, they were not addressed as the main topic of the activity, so that they could more spontaneously stem from the students' own reflections. After this activity, the participants were asked to devise and create-in a timeframe of $48 \mathrm{~h}$ - photographic routes through some of the "significant" places identified during the previous activity. Despite a general plan of the route existed beforehand, they were also given the freedom to move as they wished, drawing inspiration as they went around the city. In this case too, the photo-route technique is inspired by research that has shown how the experience of photographing "on the move" - that is, in the context of urban explorationfacilitates the assumption of an open, multisensorial and explorative approach towards the urban space, in view of grasping and transmitting meanings and atmospheres that might usually escape the attention (Pyyry 2015). So that the routes could be reconstructed, the participants were asked to take the images with the GPS signal on, to geo-locate the photographs. Then, in a first, more "technical" collective activity, the images were loaded onto GIS software and some of the routes taken in the city were reconstructed along with the participants (Fig. 2).

Lastly, a final meeting was dedicated to the students' presentation of the routes that they followed. On this occasion, they could illustrate and discuss a 
Fig. 2 A selection of photo-routes developed by participant students Source: elaborated by Stefano

Bartolini, 2020

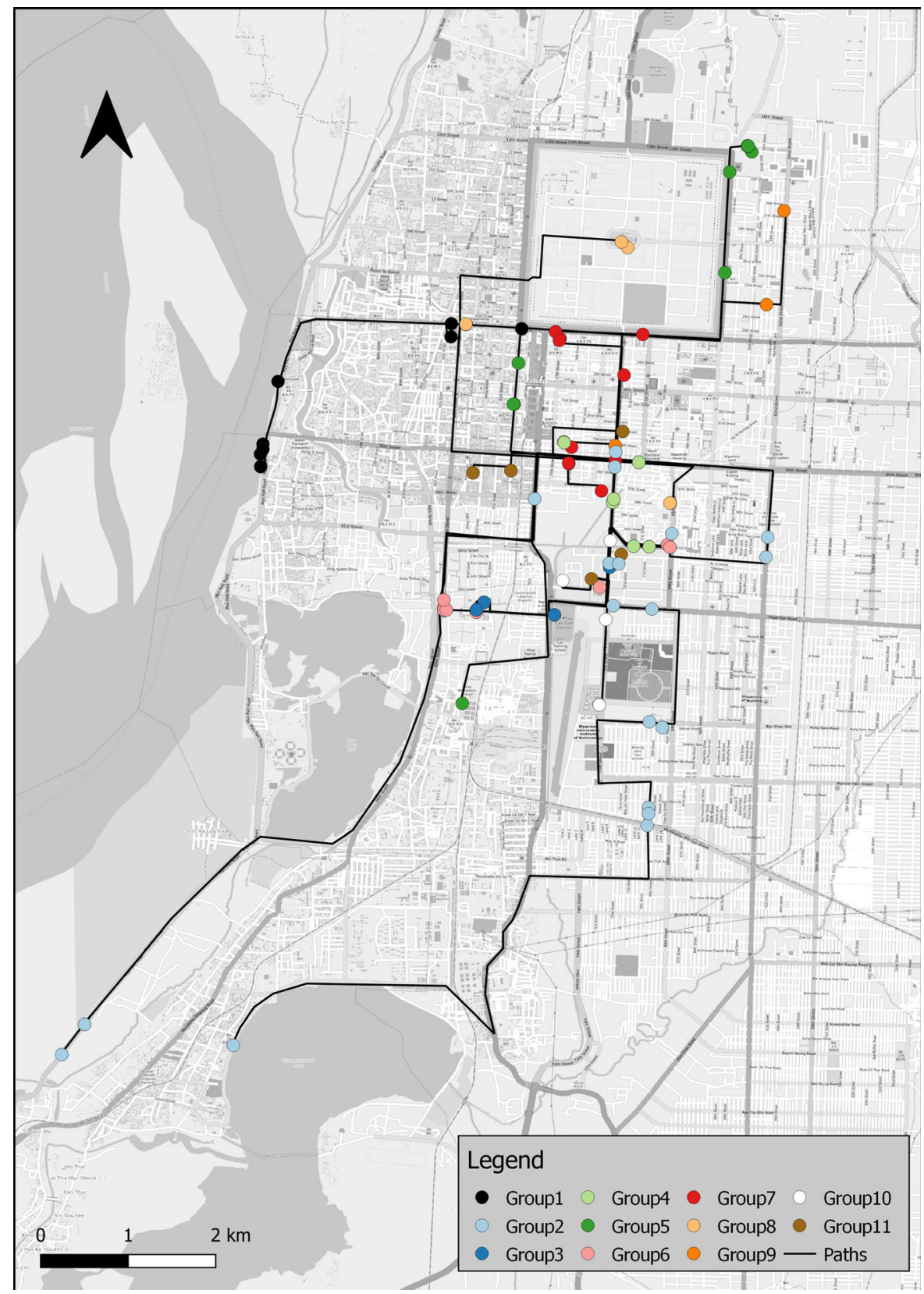

selection of the photographs taken together with their fellow students and researchers.

In total, 11 photo-routes were created and presented, by 16 out of 21 students. It must be specified that participation was voluntary and not all studentsowing to other university or personal commitmentswere able to attend all the meetings on a regular basis. In five cases, participants preferred to work in pairs-a possibility explicitly set out and illustrated by the researchers-for reasons linked to sharing the same idea for a route, except in one case when the motives were linked to having a perception of greater security when moving around the city.

Generally, the students got around on foot or devised their route as a "pedestrian" itinerary. In some cases, they went around by scooter. Generally speaking, the activity was given a very positive welcome and met with enthusiasm, even though upon first 
impact it was seen as "distant" from the methodologies they were used to at the university.

As illustrated by Table 1, which sums up the main themes of each route, on the whole the photo-routes dwelled on a range of multiple, topics, levels of interpretation and spaces and it would not be possible—nor necessary - to give an exhaustive reading of their contents. However, the participants' accounts and pictures revealed three main recurrent patterns: i) students' everydayness; ii) inbetween past and future; iii) urban issues at stake.

\section{Students' everydayness}

The first group of images taken by the participants focus on the everydayness of being a student in Mandalay, providing reflections and testimonies relating to student life inside and outside the university. The choice to concentrate on such a highly subjective dimension is not only linked to the participants' obvious condition of being students, but reveals a deeper appraisal of their life course and relationship with the city. Indeed, not only do the images and comments that can be grouped under this category concentrate on how the participants live the city, but also on how the fact of living in the city has profoundly changed the lives of some of them, and especially those who came to Mandalay to attend the university from other areas of the country. As M.M. says: "when I first arrived in Mandalay, I didn't know anything about the Internet or about the social life of a city, since I am from a small town. Now, everything is normal to me". P.P. continues in the same line of thought:

My everyday lifestyle has changed along with the city in the last five years. When I came to Mandalay to attend university, I couldn't use the Internet very well as there is a bad connecting system in my native town. But when I arrived in Mandalay, I was able to use the Internet and

Table 1 Short description of students' photo-routes Source: elaborated by the author

\begin{tabular}{|c|c|c|c|}
\hline No. & Participants & $\begin{array}{l}\text { Number of } \\
\text { images }\end{array}$ & Short description of the photo-walk \\
\hline 1 & Z.Z. and Y.Y. & 9 & $\begin{array}{l}\text { Their tour took in some of the main tourist attractions in the city, going from the ferry } \\
\text { moorings on the River Irrawaddy to the Royal Palace. }\end{array}$ \\
\hline 2 & S. & 17 & $\begin{array}{l}\text { His tour was an urban exploration through Mandalay by scooter, moving in the traffic, } \\
\text { through neighbourhoods under construction and reflections on the changes underway in } \\
\text { the city. }\end{array}$ \\
\hline 3 & S.T. & 5 & $\begin{array}{l}\text { His tour followed a typical day of a student at Mandalay University, from the classrooms } \\
\text { and places to meet friends and eat the traditional Kyat-Yoedayar together and relax at the } \\
\text { end of the day. }\end{array}$ \\
\hline 4 & P.P. & 5 & $\begin{array}{l}\text { Her tour took in some sites and emblematic rites from Buddhist culture in Mandalay and } \\
\text { some symbolic places in the lives of students at Mandalay University. }\end{array}$ \\
\hline 5 & N.I. and Y.M.M. & 9 & $\begin{array}{l}\text { Their trip took in food places in Mandalay, from street food stalls, through traditional and } \\
\text { tourist restaurants to the new international fast-food chains. }\end{array}$ \\
\hline 6 & M.Z. & 8 & $\begin{array}{l}\text { Her tour recounted the places of expression of Mandalay's tangible and intangible cultural } \\
\text { heritage: pagodas, monuments, theatres and craft workshops. }\end{array}$ \\
\hline 7 & K.Y. and Y.M. & 4 & $\begin{array}{l}\text { Their walk took in some sites of Mandalay cultural heritage: the Royal Palace and indoor } \\
\text { market. }\end{array}$ \\
\hline 8 & M.M. and S.T. & 8 & $\begin{array}{l}\text { Their trip went to symbolic places to raise awareness of the main urban problems in } \\
\text { Mandalay: the traffic, pollution and lack of safety at work. }\end{array}$ \\
\hline 9 & K.Z. & 11 & $\begin{array}{l}\text { His tour covered different aspects of city life: busy roads, tea shops, Christian churches, } \\
\text { Hindu and Buddhist temples, markets and street food stalls. }\end{array}$ \\
\hline 10 & J.J. & 10 & $\begin{array}{l}\text { Her tour through craft workshops showed the city's intangible cultural heritage, but at the } \\
\text { same time workplaces which fail to meet all of the health and safety standards. }\end{array}$ \\
\hline 11 & H.H.H. and Y.M. & 6 & $\begin{array}{l}\text { Their trip by scooter took them from Mandalay University to the new Mingalar Mandalay } \\
\text { shopping district. }\end{array}$ \\
\hline
\end{tabular}

The names of the participants are made anonymous by indicating the initials 
social media very well. Also, I can ride a motorbike to go from one place to another, while I couldn't ride when I first arrived here.

At the personal level, access to a large city undergoing modernization is experienced as a real rite of passage. One of the most suggestive images on the topic of everydayness was taken by S. (Fig. 3), whose trip "on the road" through the streets of Mandalay on his scooter recorded events and situations that appeared before him.

The topic of mobility and getting around a city that is perceived as extremely vast, busy and chaotic is mentioned as one of the first and main problems that they had to deal with in their lives as studentsinhabitants of Mandalay. As H.H.H. underlines: “three years ago I couldn't ride a motorbike and, as a consequence, I couldn't go anywhere in Mandalay. At that time if I wanted to go somewhere I was obliged to hire a car, but the price is very high. Therefore, I learned to ride, so now I can go easily everywhere." Among the various routes around the city, the images reveal a geography of Mandalay as it is lived by the students: places for hanging out like teahouses, bars and food shops, where the students meet, relax, make friends and through which they live the city (Fig. 4). As Noora Pyyry (2016, p. 106) suggests, these spaces are more than simple places to get together, they reflect the way in which "young people mark and claim spaces as their own often simply by their presence: they appropriate spaces by hanging out, even if just momentarily."

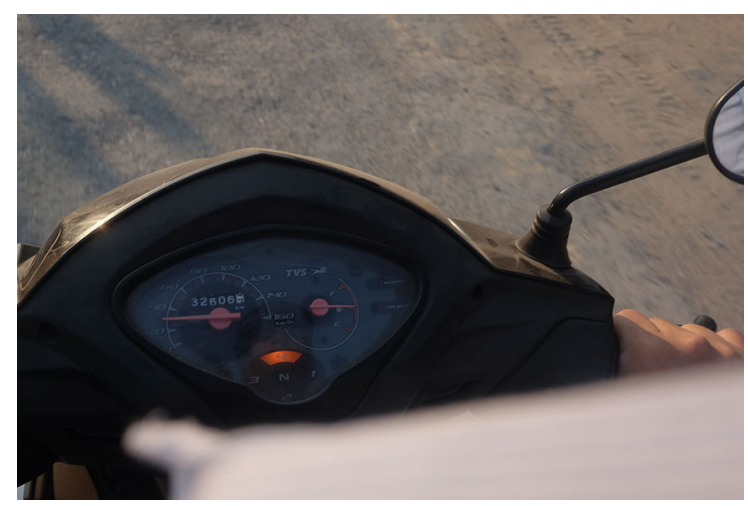

Fig. 3 With 32,606 $\mathrm{km}$ on my mileage, I like to think that 'on my motorcycle' is one of the places where I spend most of my time in Mandalay Source: photo by S., participant in the research

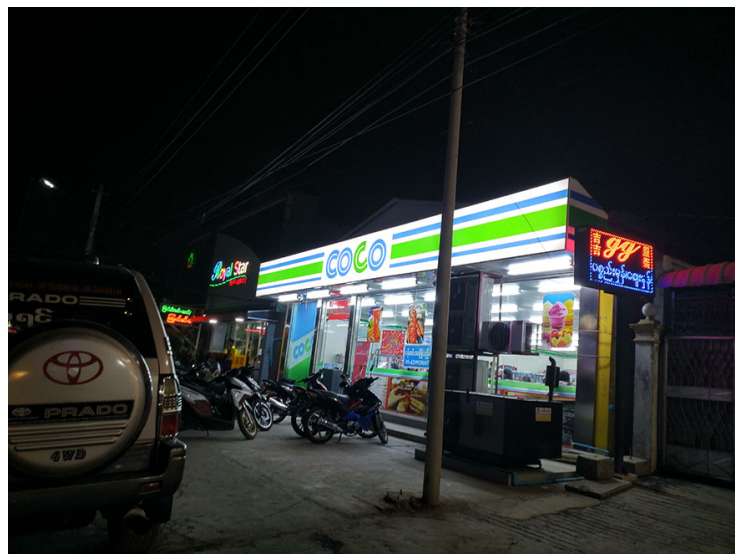

Fig. 4 Most of the students use to go to Co Co, a mini-market, to enjoy ready-made noodle and hot dog Source: photo by N.I. and Y.M.M., participants in the research

Among the various places in the students' everyday lives, the Mandalay University campus holds a particular status, both in the participants' images and their comments. It is not just the place where some participants live and where they all go to lessons, eat meals and spend part of their days. More metaphorically, the campus represents a place of shelter, a green oasis in the heart of the frenetic hubbub of the city (Fig. 5).

\section{In-between past and future}

A second group of images portrays places and symbolic situations that create a significant tension

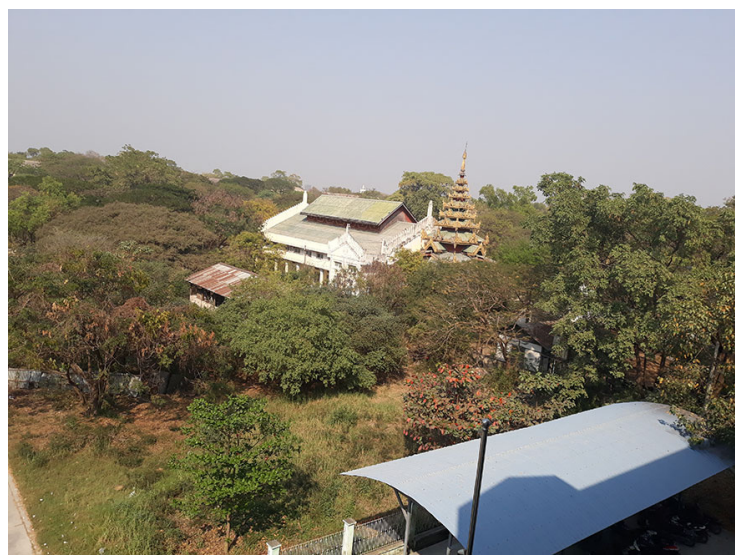

Fig. 5 Mandalay University Campus. There are so many more trees than in other places in the city Source: photo by M.M. and S.T., participants in the research 
between the past, present and future of the city. On one hand, there are shots that document some of the more codified historic, cultural and religious sites as well as the main tourist attractions of the city: Mandalay Hill, the pagodas, the moorings of the tourist ferries on the river and so on. These sites are often mentioned as a constitutive part of Mandalay's tangible cultural heritage or because of their symbolic and identity value for the whole of Theravāda Buddhist culture, such as in the case of the image of Buddha worshipped in the Mahamuni temple (Fig. 6).

In this historical-cultural approach to the urban landscape, in which the photo assumes an essentially "documentary" function, the participants seem in part to conform to a sort of touristic gaze (Urry 1990) in the narration of the city. Other shots instead capture specific components of the intangible heritage, such as traditional crafts, religious rites and ceremonies, which are evoked as representing local culture. The participants make more subjective comments and assessments on these components. On commenting a series of images on the various phases of workmanship in a gold embroidery workshop, J.J. underlines: "I've liked this place since I was a child and I'm so fascinated when the artisans work the gold. This is also one of our tourist attractions in Nan Shei (eastern part

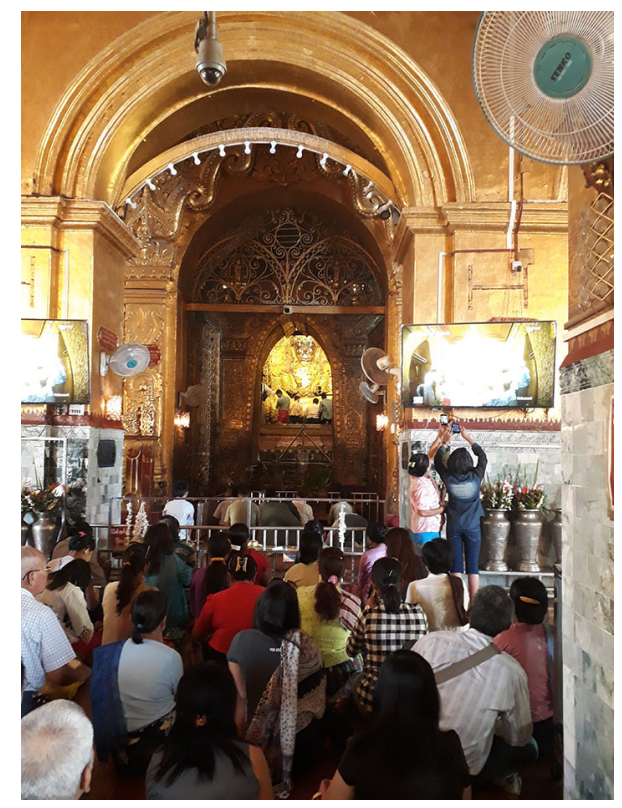

Fig. 6 Mahamuni Buddha image. This image is regarded as one of the symbols of Mandalay and reflects the religious belief of Buddhism Source: photo by P.P., participant in the research

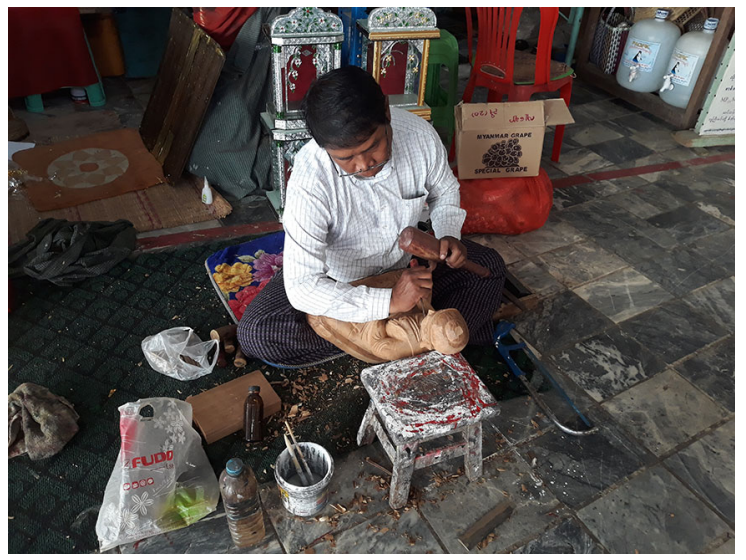

Fig. 7 Wood carving is one of Myanmar's traditional handicrafts but now this tradition is becoming rarer and has almost disappeared in some places Source: photo by M.M. and S.T., participants in the research

of the Palace)." M.M. and S.T. instead show their concern for the progressive disappearance of traditional crafts (Fig. 7).

In contrast to the images portraying aspects linked to identity and tradition, there are shots that dwell on the urban transformations underway and the new spaces that the participants perceive to be taking on a central role (Fig. 8).

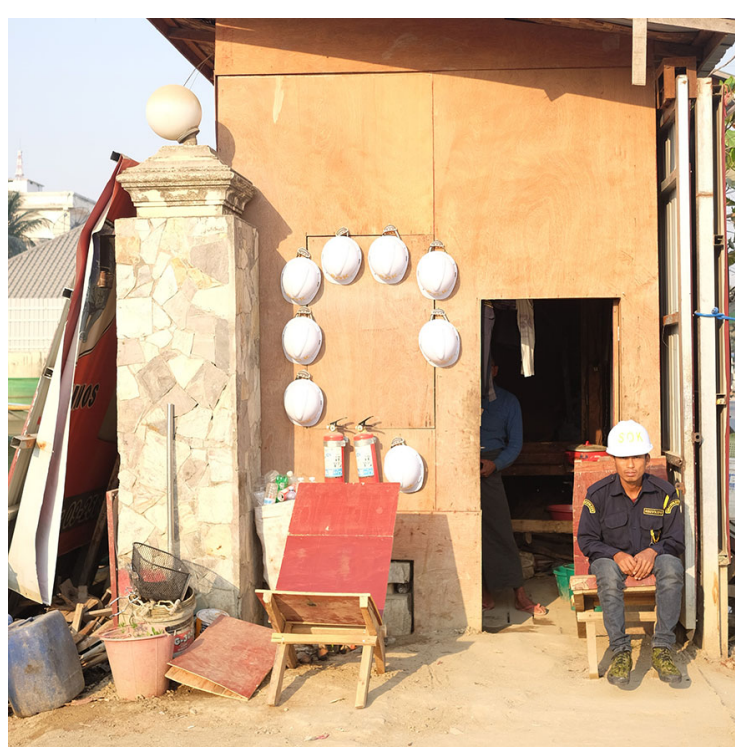

Fig. 8 Shwe Wah Htun Street. The construction site was off limits but I think this photo of a construction worker pretty much shows what's happening in the new town: building, building, building! Source: photo by S., participant in the research 
In particular, these areas are newly built residential neighbourhoods and big shopping malls in line with the international model, which are springing up in particular in the southern part of the city. These places, which house shops and outlets selling foreign-made and Western-style products and where the first Western international chains are setting up, are designed to cater for the local middle-high class. The fact that one of these-Mingalar Mandalay-is close to the University Campus makes it one of the places in the city most visited, mentioned and appreciated by the participants (Fig. 9).

The photo-route by N.I. and Y.M.M., centred around the topic of food, is particularly significant in this tension between tradition and modernization, local and global. The two participants record various urban markets and street food stalls where you can eat "typical" meals of Burman tradition, ending up at the "Lotteria" fast food located at the Mingalar Mandalay complex (Fig. 10).

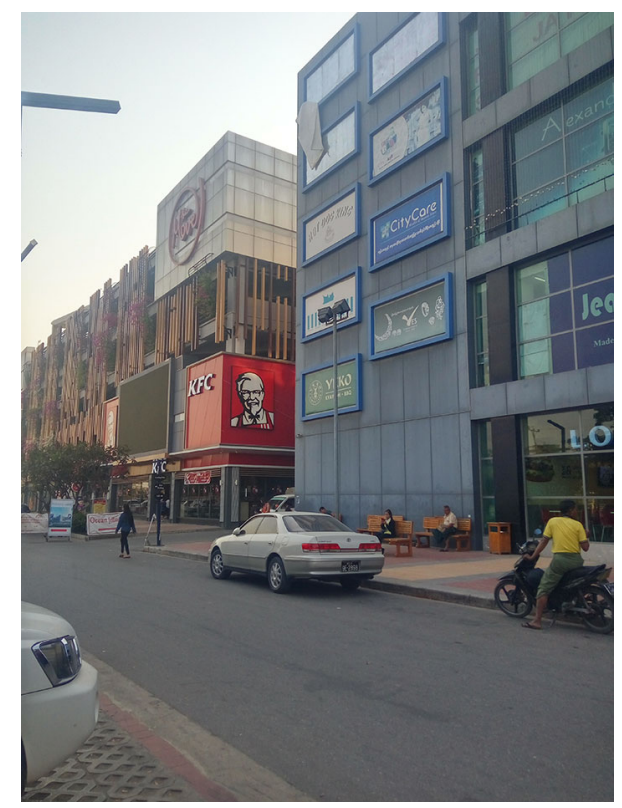

Fig. 9 The Mingalar Mandalay area is the place that has changed the most in the city. It was a plain place. But now it has become one of the most popular places in the city, with a shopping centre, sports stadium and sports academy, hotel, banks and training centres Source: photo by H.H.H. and Y.M., participants in the project

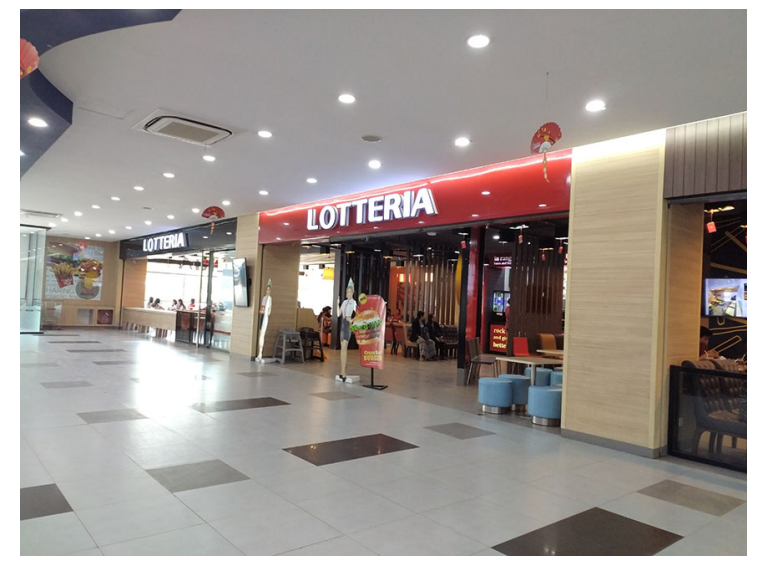

Fig. 10 Lotteria. The fast food chain we like the most. We can buy the things that we need in one place Source: photo by N.I. and Y.M.M., participants in the project

\section{Urban issues at stake}

As the city and lifestyles change, new urban issues are arising. Many participants used the camera to highlight problems and issues at stake in the growing metropolis. In the participants' view, urban growth has both positive and negative sides. According to N.N.: "a positive change is that most of the people are able to buy new cars and build new houses and apartments with many floors, which are some of the features of well-improved cities". According to H.H.: "People keep on building new apartments and agricultural land is lost. There is almost no free space and no playgrounds for children to play. Also consider the number of industries: the areas around are polluted and cannot get enough fresh air." Traffic is one of the main issues raised by the participants' pictures, and the increasing number of private cars and motorbikes is reported as a cause of traffic jams, pollution, accidents and, more generally, a "dusty, crowded and hot place", as N.I., one of the students, defines the city's atmosphere (Figs. 11 and 12).

The list of urban problems is extremely long. Along with air pollution, the lack of infrastructures, bad maintenance of the existent ones and insecurity, waste management is another main issue on which the students focus their attention (Fig. 13).

Environmental issues offer some participants the pretext to insert positive messages in their tour: this is the case of K.Z., who underlines how greater environmental awareness can help to deal with, and possibly resolve, some urban problems (Fig. 14). 


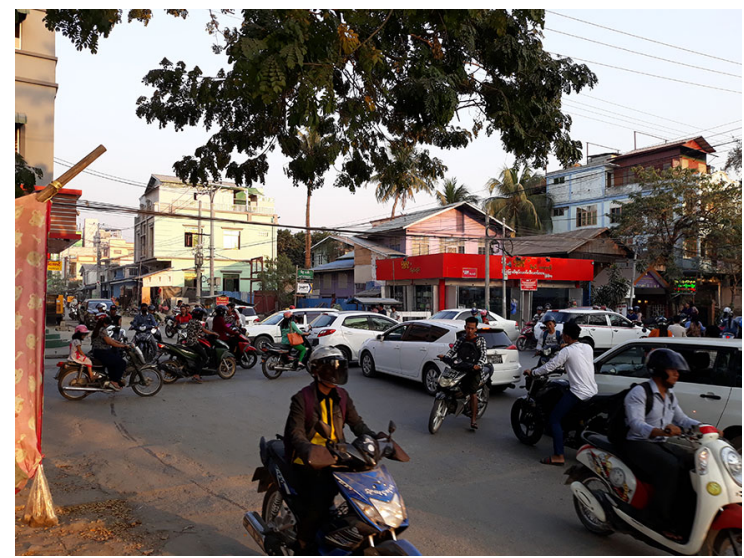

Fig. 11 This is the corner of 69 and 41 Streets, one of the places often affected by traffic jams, accidents and robberies. This place needs traffic lights and security Source: photo by M.M. and S.T., participants in the research

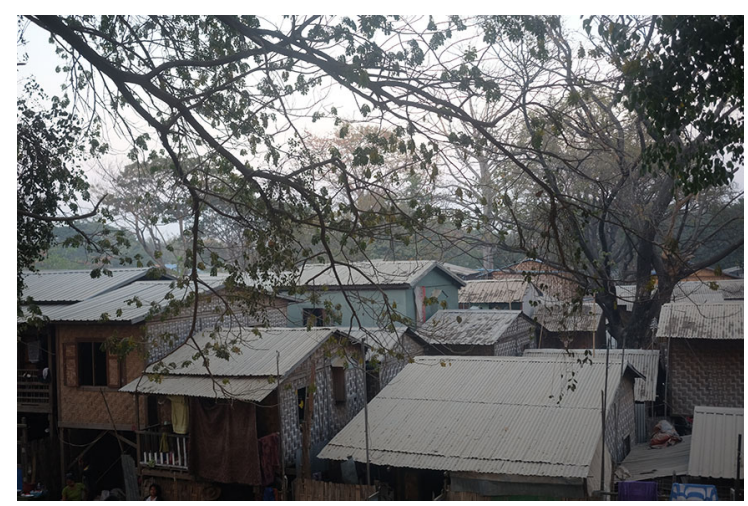

Fig. 12 Myo Patt Street. The houses near it have blankets of dust on their roofs from all the highway traffic! Source: photo by S., participant in the research

Processing the urban change

It has been observed how, more than more conventional techniques, the use of experimental, creative and storytelling approaches to explore and recount space is capable of grasping the "processual, polyvocal, always-becoming" (Price 2004, p. 1) nature of places. In addition, "other ways of storying landscape" may help make "sense of transience" in space (Desilvey 2012, pp. 32-33; see also Ward 2014). In the same way, according to Lombard (2013p. 28) "photos taken by residents tend to illustrate the complexity of place more successfully than photos taken by the researcher". In a context undergoing great transformation such as that of Mandalay, photo-routes proved

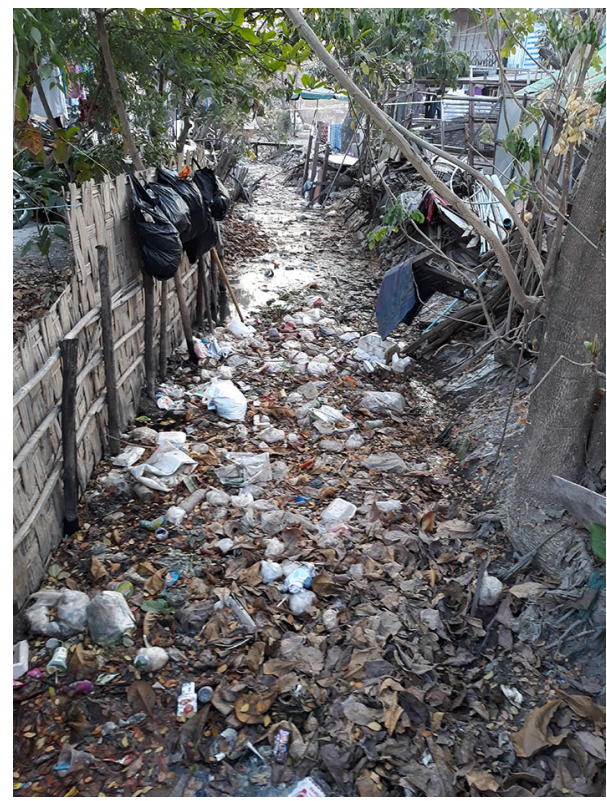

Fig. 13 The water channels are blocked by rubbish. So, these channels are the main cause of floods in the rainy season and the reproduction of mosquitoes Source: photo by M.M. and S.T., participant in the research

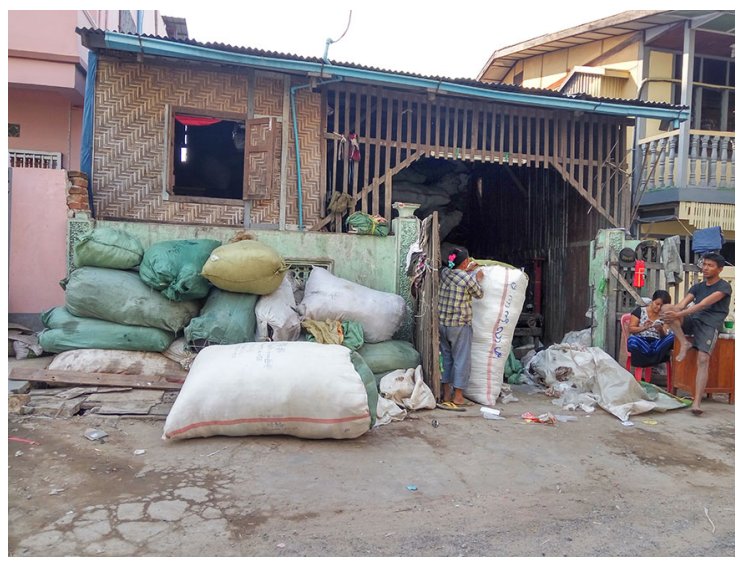

Fig. 14 Recycling shop: I want to show that Mandalay's citizens don't just dump trash, they also sell or recycle it Source: photo by K.Z., participant in the research

to be an effective methodology both in view of capturing and immortalizing the manifestation of this sense of transience in the urban space. Not only that, it is a way of expressing a critical and conscious gaze over the city, its current changes, and the relationship between its subjectivities and the spaces in the city. In other words, the photo-routes enabled the urban 
change to be processed at different, interwoven levels of meaning.

A first level dwells on the costs and the issues at stake in the urban transition underway. Congestion, pollution, waste, the lack of services and infrastructure, precarious working conditions and lack of safety are some of the examples captured by the participants through a topograhic kind of photographic approach that pinpoints them in symbolic places on the city map. These places are evidence of the awareness that the modernization process is not happening in a linear manner, but that it produces rents, friction, a lack of homogeneity and injustices. S. shows this well, capturing the roofs of the houses in one of Mandalay's slums covered in the dust whipped up by the nearby urban traffic (Fig. 12). In the eyes of the participants, these problems do not only represent a challenge for the city governance, but also a field that requires active involvement, initiative and responsibility on the part of the citizenry as hoped for by K.Z. (Fig. 14).

On a more symbolic level, from the participantstudents' images it emerges how the changes underway directly affect the topic of the identity of places, and therefore of the people who inhabit them. The contrast between the testimonies of the cultural heritage and tradition of Mandalay, which the students capture and reproduce with pride, and places that embody international and global models, which the participants in general declare they appreciate, shows a precarious and uncertain balance between attachment to the past and attraction to the future, between lifestyles and city models which appear different. The tension between these two poles generates a sort of sense of restlessness and insecurity, mainly deriving from realizing the progressive or potential disappearance of some practices, know-how or lifestyles perceived as part of the country's identity. At the same time, the fact that more traditional places and more "modern" spaces are included in a good part of the photo-routes shows how the participants live and frequent both, giving rise to everyday geographies that hybridize and mix elements belonging to several dimensions, origins and tendencies. This result confirms the existence of a tension between tradition and modernity in urban identities in Myanmar (Roberts 2019, p. 406), and especially in Mandalay, still viewed as the stronghold of Burmese tradition. It is also a fact in line with what has already been highlighted by Rick and Franck (2016) in a previous study on the changes caused by "contact" between young Burmans and international tourists in Bagan, again in Myanmar: while on one hand, the young people perceive a sense of confusion and conflict in the relationship with other cultures, on the other they are starting to practise and implement their own "hybrid" and "glocalized" versions of identity.

A last level of meaning concerns the subjective and personal dimension of their relationship with the city. At this level, the activity carried out-including the initial activities of reflecting on the topic of lived space and the collective comments on the photo-routesenabled the participants to form and share reflections of an introspective nature on their life course and how this is entangled with the city. The images and above all the comments give reflections and cues on the highly in-becoming nature of student life which is constantly on the move (both in space, and time) and enable the participants to tell their story by storying the city: on one hand, by sharing the profound changes that the encounter with Mandalay has generated in their lives, especially for those who come from other, less densely inhabited areas of the country; on the other hand, by revealing their geographies and everyday strategies to make the city "their own" and share spaces and places with their peers and other people of their age.

\section{Conclusions}

This paper gives the results of a research-intervention performed in Mandalay, Myanmar, in the field of visual studies, and more precisely auto-photography, involving the creation and realization of photoroutes through the city. As in other projects centred around visual methodologies, photography was used to capture "a visual impression of the residents' sense of place" (Lombard 2013) and, in the specific case of Mandalay, the perception of the change underway in a city undergoing rapid transformation both concerning the urban space and in social and economic terms.

The research was driven by the idea of questioning young people to find out their point of view on the transformations going on in one of the most rapidly changing areas of the planet, that is Southeast Asia and Myanmar. Indeed, this paper argues that cities in this macro region have not been sufficiently studied "from below", leaving urban change difficult to be fully 
analyzed and understood. This is even truer if we consider highly intangible features of urban change, such as that related to political, societal and cultural aspects, local identities, and everyday experiences and perceptions. While it calls for further research in this field of study, the paper provides a contribution in it, restituting the lived experience of social change in the city of Mandalay.

The research intervention saw the participation of 21 students from Mandalay University, involved in an international exchange programme with the University of Florence. As well as being induced by the nature of the cooperation project, the choice to work with a strongly characterized group of participants was also motivated by the interest to find out and evoke the viewpoint of a group of young adults on the urban transformation processes in Mandalay. The intervention, clearly inspired by the principles of more-than representational theories, questioned the participants on their spatial practices, the places and routes that represented their everyday lives and at the same time expressed the transformations underway in the city.

Although the participants' status of students evidently influenced the proposition of some topics and spaces, the always in-becoming nature of place was processed at three interwoven levels of meaning: students' everydayness; in-between past and future urban issues at stake. From a methodological point of view, the activity photo-route tool-and more in general creative and multi-modal methodologiesproved to be particularly effective in stimulating a critical gaze on the city and the changes underway, to acquire awareness of the constantly in-becoming nature of the places and reflect in an introspective manner on their own life course in relation to the city.

Nevertheless, numerous paths for reflection remain open-which could not be investigated here-concerning the treatment and reading of the visual material generated in similar interventions and research (Lombard 2013). By way of example, in the case of Mandalay, we can mention the researcher's "fundamentally problematic" role (Smith 2010, p. 190) in summing up the elements deemed most significant in the various photo-routes, including and excluding certain materials when putting together the text of a paper, and more in general reconstructing the story through images and comment. Nevertheless, we think that, if declared and laid bare, these and other problematic aspects can represent a useful field of reflection for increasingly conscious use of methodologies such as visual methods with a great heuristic, analytical and descriptive potential to story places.

Acknowledgements Open access funding provided by Università degli Studi di Firenze within the CRUI-CARE Agreement.

Funding This work was carried out in the framework of the activities of the ERASMUS + Teaching Staff Mobility (STT) KA 107 N. 2017-1-IT02-KA107-035582 between the Universities of Florence (Italy) and Mandalay (Myanmar).

\section{Compliance with ethical standards}

Conflict of interest The author declares that he has no conflicts of interest.

Informed consent was obtained from all individual participants involved in the study.

Open Access This article is licensed under a Creative Commons Attribution 4.0 International License, which permits use, sharing, adaptation, distribution and reproduction in any medium or format, as long as you give appropriate credit to the original author(s) and the source, provide a link to the Creative Commons licence, and indicate if changes were made. The images or other third party material in this article are included in the article's Creative Commons licence, unless indicated otherwise in a credit line to the material. If material is not included in the article's Creative Commons licence and your intended use is not permitted by statutory regulation or exceeds the permitted use, you will need to obtain permission directly from the copyright holder. To view a copy of this licence, visit http://creativecommons.org/licenses/by/4.0/.

\section{References}

ADB. (2014). Myanmar. Unlocking the potential. Manila: Asian Development Bank.

ADB (2015). Mandalay urban services improvement project. Toward a green Mandalay. Asian Development Bank, available at http://www.adb.org/publications/towardgreen-mandalay. Accessed 29 July 2020.

Anderson, B., \& Harrison, P. (2010). The promise of nonrepresentational theories. In B. Anderson \& P. Harrison (Eds.), Taking place. Non-representational theories and geography (pp. 1-36). London: Ashgate.

Aru, S., Memoli, M., \& Puttilli, M. (2017). The margins inbetween. A case of multimodal ethnography. City, 21(2), $151-163$.

Brenner, N., \& Schmid, C. (2015). Towards a new epistemology of the urban? City, 19(2-3), 151-182.

Bunnell, T., Goh, D. P. S., \& Ng, H. (2019). Aspiration in urban(izing) Southeast Asia. In R. Padawangi (Ed.), Routledge handbook of urbanization in Southeast Asia (pp. 54-63). Abingdon: Routldege. 
Cattedra, R., Idrissi-Janati, M., Giua, R., \& Puttilli, M. (2018). Geografie ed emozioni del quotidiano. Racconti fotografici di giovani abitanti a Fès. Rivista Geografica Italiana, 125, 289-312.

Cresswell, T. (2012). Review essay: Nonrepresentational theory and me: Notes from an interested sceptic. Environment and Planning D: Society and Space, 30(1), 96-105.

Crouch, D. (2017). Space, living, atmospheres, affectivities. In M. Nieuwenhuis \& D. Crouch (Eds.), The question of space. Interrogating the spatial turn between disciplines (pp. 1-22). London-New York: Rowland \& Littlefield.

DeSilvey, C. (2012). Making sense of transience: an anticipatory history. Cultural Geographies, 19(1), 31-54.

Dicks, B., Bambo, S., \& Coffey, A. (2006). Multimodal Ethnography. Qualitative Research, 6(1), 77-96.

Dobermann, T. (2016). Urban Myanmar. Policy note. London: International Growth Centre.

Dodman, D. (2003). Shooting in the city: an authophotographic exploration of the urban environment in Kingston. Jamaica Area, 35, 293-304.

Evans, B. (2008). Geographies of Youth/Young People. Geography Compass, 2(5), 1659-1680.

Everts, J., Lahr-Kurten, M., \& Watson, M. (2011). Practice matters! Geographical inquiry and theories of practice. Erdkunde, 65(4), 323-334.

Fairay, T. (2017). Whose photo? Whose voice? Who listens? 'Giving', silencing and listening to voice in participatory visual projects. Visual Studies, 33(2), 111-126.

Forbes, H. (2019). Migration, Informal Settlement, and Government Response: The Cases of Four Townships in Yangon, Myanmarz. Moussons Recherches en Sciences Sociales sur l'Asie du Sud-Est, 33, 95-117.

Gong, X. (2019). The belt \& road initiative and China's influence in Southeast Asia. The Pacific Review, 32(4), $635-665$.

Governa, F., \& Puttilli, M. (2016). After a revolution: public spaces and urban practices in the core of Tunis. In M. Lancione (Ed.), Rethinking life at the margins. The assemblage of contexts, subjects, and politics (pp. 42-60). New York: Routledge.

Griebling, S., Vaughn, L. M., Howell, B., Ramstetter, C., \& Dole, D. (2013). From passive to active voice: using photography as a catalyst for social action. International Journal of Humanities and Social Science., 3(2), 16-28.

Heinrich Böll Stiftung Yangon. (2019). China-Myanmar economic corridor: Challenges and opportunities. Yangon Office: Heinrich Böll Stiftung.

Holloway, S., \& Valentine, G. (2000). Children's geographies: Living, playing, learning and transforming everyday worlds. London and New York: Routledge.

Hong, M. S. (2020). Being and becoming 'dropouts': Contextualizing dropout experiences of youth migrant workers in transitional Myanmar. International Journal of Qualitative Studies in Education. https://doi.org/10.1080/09518398. 2020.1717665 .

Hörschelmann, K., \& Schäfer, N. (2005). Performing the global through the local: globalisation and individualisation in the spatial practices of young East Germans. Children's Geographies, 3(2), 219-242.
Hörschelmann, K., \& Schäfer, N. (2007). 'Berlin is not a foreign Country, stupid!' Growing up global in Eastern Germany. Environment and Planning A, 39(8), 1855-1872.

Hunt, M. A. (2014). Urban photography/Cultural geography: Spaces, objects, events. Geography Compass, 8(3), 151-168.

Hurdley, R., \& Dicks, B. (2011). In-between practice: Working in the 'Thirdspace' of sensory and multimodal methodology. Qualitative Research, 11(3), 277-292.

Huynh, D. (2018). The promises of planning under the NLD. Toronto: Tea Circle-Center for Southeast Asian Studies.

Jones, G. W. (2019). Some conceptual and methodological issues in studying urbanization in Southeast Asia. In R. Padawangi (Ed.), Routledge handbook of urbanization in Southeast Asia (pp. 90-100). Abingdon: Routldege.

Khaing, N.Y., \& Zau Zin Myat, S. (2019). Resisting Relocation: A Community Study of the Slum Dwellers. Living and Working in Mingun Jetty. Final project for the course in Urban Political Geography, University of Florence, Master's degree in Geography, Spatial Management, Heritage for International Cooperation, Academic Year 2018-2019.

Kim, Y. (2018). Mandalay, Myanmar: The remaking of a Southeast Asian hub in a country at the crossroads. Cities, 72(B), 274-286.

Kyed, H. M. (2019). Informal settlements and migrant challenges in yangon. Moussons. Recherches en Sciences Sociales sur l'Asie du Sud-Est, 33, 65-94.

LaGeS. (2016). Sustainable destination plan for the ancient cities of upper Myanmar. Mandalay, Amarapura, Innwa, Sagaing, Mingun. Firenze: Polistampa.

Leonard, M., \& McKnight, M. (2015). Look and tell: using photo-elicitation methods with teenagers. Children's Geographies, 13(6), 629-642.

Lombard, M. (2013). Using auto-photography to understand place: reflections from research in urban informal settlements in Mexico. Area, 45(1), 23-32.

Lorimer, H. (2005). Cultural geography: The busyness of beingmore-than-representational. Progress in Human Geography, 29(1), 83-94.

Malik, J. M. (2018). Myanmar's role in China's maritime silk road initiative. Journal of Contemporary China, 27(111), 362-378.

Massey, D. (1998). The spatial construction of youth cultures. In T. Skelton \& G. Valentine (Eds.), Cool places: Geographies of youth cultures (pp. 121-129). London and New York: Routledge.

Matelski, M., \& Sabrié, M. (2019). Challenges and Resilience in Myanmar's Urbanization: A Special Issue on Yangon. Moussons. Recherches en Sciences Sociales sur l'Asie du Sud-Est, 33, 11-31.

McQuoid, J., \& Dijst, M. (2012). Bringing emotions to time geography: the case of mobilities of poverty. Journal of Transport Geography, 23, 26-34.

Meth, P., \& McClymont, K. (2009). Researching men: the politics and possibilities of a qualitative mixed-methods approach. Social and Cultural Geography, 10, 909-925.

Naafs, S., \& Skelton, T. (2018). Youthful futures? Aspirations, education and employment in Asia. Children Geographies., 16(1), 1-14.

Nyo, N. (2016). Cultural heritage places around Mandalay area (Myanmar), unpublished report used for the preparation of 
the Sustainable Destination Plan for the Ancient Cities of Upper Myanmar by the LaGeS-Laboratory of Social Geography-University of Florence.

Packard, J. (2008). 'I'm gonna show you what it's really like out here': the power and limitation of participatory visual methods. Visual Studies, 23(1), 63-77.

Pauwels, L. (2015). 'Participatory' visual research revisited: A critical-constructive assessment of epistemological, methodological and social activist tenets. Ethnography, 16(1), 95-117.

Price, P. (2004). Dry place: Landscapes of belonging and exclusion. Minneapolis: University of Minnesota Press.

Puttilli, M., Cattedra, R., Idrissi Janati, M., \& Giua, R. (2016). Youth geographies of everyday life. Methodological notes from a project of photographic storytelling in Fez. $J$ Reading - Journal of Research and Didactics in Geography, 2, 87-94.

Pyyry, N. (2015). 'Sensing with' photography and 'thinking with' photographs in research into teenage girls' hanging out. Children's Geographies, 13(2), 149-163.

Pyyry, N. (2016). Learning with the city via enchantement: photo-walks as creative encounters. Discourse: Studies in the Cultural Politics of Education, 37(1), 102-115.

Rhoads, E. L. (2018). Forced evictions as urban planning? Traces of colonial land control practices in Yangon. Myanmar. State crime, 7(2), 278-305.

Rhoads, E. L., \& Wittekind, C. T. (2018). Rethinking land and poverty in a "transitioning" Myanmar: Representations of isolation, neglect, and nature decline. The Journal of Burma Studies, 22(2), 171-213.

Rick, A.-K., \& Franck, A. K. (2016). Tourism development in Bagan, Myanmar: perceptions of its influences upon young peoples' cultural identity. Tourism Planning and Development, 13(3), 333-350.

Rieger, J. H. (1996). Photographing social change. Visual sociology, 11(1), 5-49.

Rimmer, P. J., \& Dick, H. (2019). Gateways, corridors and peripheries. In R. Padawangi (Ed.), Routledge handbook of urbanization in Southeast Asia (pp. 9-30). Abingdon: Routldege.

Roberts, J. L. (2019). In search of urban identities in Myanmar. In R. Padawangi (Ed.), Routledge handbook of urbanization in Southeast Asia (pp. 400-410). Abingdon: Routldege.

Rose, G. (1996). Teaching visualised geographies: towards a methodology for the interpretation of visual materials. Journal of Geography in Higher Education., 20(281), 294.

Sabrié, M. (2019). Yangon "Emerging Metropolis": Challenges for the Authorities and Resilience of the Yangonites. Moussons Recherches en Sciences Sociales sur l'Asie du Sud-Est., 33, 33-64.

Savić, J. (2017). Sense(s) of the city: Cultural mapping in Porto, Portugal. City, culture and society., 11, 12-19.

Schatzki, T. R. (2001). Introduction: practice theory. In T. R. Schatzki, K. Knorr Cetina, \& E. Savigny (Eds.), The practice turn in contemporary theory (pp. 1-13). London: Routledge.

Schindler, S. (2017). Towards a paradigm of Southern urbanism. City, 21(1), 47-64.

Schlemper, M. B., Stewart, V. C., Shetty, S., \& Czajkowski, K. (2018). Including students' geographies in geography education: Spatial narratives, citizen mapping and social justice. Theory \& Research in Social Education, 46(4), 603-641.

Sheng, Y.-K. (2011). Urban challenges in South-East Asia. Paper presented at the 5th Asia-Pacific Urban Forum organized by the UN Economic and Social Commission for Asia and the Pacific (UN ESCAP), Bangkok, Thailand.

Sheng, Y.-K. (2019). Peri-urban transformations in Southeast Asia. In R. Padawangi (Ed.), Routledge handbook of urbanization in Southeast Asia (pp. 31-42). Abingdon: Routldege.

Simonsen, K. (2007). Practice, spatiality and embodied emotions: An outline of a geography of practice. Human Affairs, 17, 168-181.

Skelton, T. (2009). Children's Geographies/Geographies of Children: Play, Work, Mobilities and Migration. Geography Compass, 3(4), 1430-1448.

Skelton, T. (2013). Young people's urban im/mobilities: Relationality and identity formation. Urban Studies, 50(3), 467-483.

Smith, F. M. (2010). Working in different cultures. In N. Clifford \& G. Valentine (Eds.), Key methods in Geography (pp. 179-193). London: Sage.

Sun Y. (2019). Slower, smaller, cheaper: the reality of the China-Myanmar Economic Corridor. Frontier Myanmar, Thursday, September 26: https://frontiermyanmar.net/en/ slower-smaller-cheaper-the-reality-of-the-chinamyanmar-economic-corridor (last access April 25, 2020).

Thant Myint, U. (2011). Where China meets India. Burma and the New Crossroads of Asia. New York: Farrar, Strauss, and Groux.

Thrift, N. (2008). Non-representational theory: Space/Politics/ Affect. London: Routledge.

Taidong, Z. (2019). Aligning the belt and road initiative with Myanmar's sustainable development plan: Opportunities and challenges. In G. Sen, M. Leach \& J. Gu (Eds.), The belt and road initiative and the SDGs: Towards equitable, sustainable development, IDS Bulletin 50.4, Brighton: IDS.

UN-Habitat. (2015). The State of Asian and Pacific Cities. United Nations Human Settlements Programme (UNHabitat): Urban transformations. Shifting from quantity to quality.

Union of Myanmar (The Republic of). (2016a). Rapid urban diagnostic report. Nay Pyi Taw: Department of Urban and Housing Development, Ministry of Construction.

Union of Myanmar (The Republic of) (2016b). Urban development plan for Mandalay 2040. In: The Republic of the Union of Myanmar. Urban development plan for regional cities. Mandalay, Pathein and Mawlamyine. Final Report.

Urry, J. (1990). Tourist gaze: Leisure and travel in contemporary societies. London: Sage.

Valentine, G. (2003). Boundary crossings: transitions from childhood to adulthood. Children's Geographies, 1(1), 37-52.

Vaughan E. (2017). Myanmar Country Report. ESPA (Ecosystems Services for Poverty Alleviation Directorate) and ACCCRN (Asian Cities, Climate Change Resilience Network). 
Wang, C. (2006). Youth participation in photovoice as a strategy for community change. Journal of Community Practice, 14, 147-161.

Ward, M. (2014). The art of writing place. Geography Compass, 8(10), 755-766.

Woodley-Baker, R. (2010). Private and public experience captured: young women capture their everyday lives and dreams through photo-narratives. Visual Studies, 24(1), $19-25$.

World Bank (2015). East Asia's changing urban landscape. Measuring a decade of spatial growth. Washington D.C.: International Bank for Reconstruction and Development/ The World Bank.

Worth, N. (2009). Understanding youth transition as 'becoming': identity, time and futurity. Geoforum, 40, 1050-1060.

Yeung, Y.-M. (2002). Globalization and Southeast Asian urbanism. Asian Geographer, 21(1-2), 171-186.
Yeung, Y.-M. (2011). Rethinking Asian cities and urbanization: four transformations in four decades. Asian Geographer, 28(1), 65-83.

Zhao, H., \& Yang, M. (2012). China-Myanmar Economic Corridor and its Implications. East Asian Policy, 4(2), 21-32.

Zhou, T. (2019). Aligning the belt and road initiative with Myanmar's sustainable development plan: Opportunities and challenges. Institute of Development Studies Bulletin, 50(4), 69-88.

Publisher's Note Springer Nature remains neutral with regard to jurisdictional claims in published maps and institutional affiliations. 